\title{
Effect of Magnetic Treatment on Surface Tension and Water Evaporation
}

\author{
Hamza Ben Amor ${ }^{1,2}$, Anis Elaoud ${ }^{1 *}$, Nahla Ben Salah ${ }^{4}$ and Khaled Elmoueddeb ${ }^{3}$ \\ ${ }^{1}$ Laboratory of Natural Treatment Water, Water Research and Technologies Center -Borj Cedria, Tunisia \\ ${ }^{2}$ University of Carthage, National Institute of Agronomic,Tunisia \\ ${ }^{3}$ Higher School of Engineers Medjez Elbeb, Tunisia \\ ${ }^{4}$ Laboratory of probabilities and statistic, Faculty of Sciences of Sfax, Tunisia
}

Received 12 June, Accepted 17 Sept 2017, Available online 25 Sept 2017, Vol.5, No.3 (Sept 2017)

\begin{abstract}
In Tunisia, the availability of water resources is an important issue in agriculture, drinking water and industry. It is important to note that agriculture is the most water consuming activity. However, the scarcity of water resources, both in quality and quantity, and its geographical distribution are among the main factors limiting the development of Tunisian agriculture. It is clear that the magnetic device influences the characteristics of limestone. On the other hand, there is variation in the physico-chemical characteristics of water which improves productivity and crop performance. The performance of irrigation by magnetized water is greater than irrigation by raw water. In this context, we examine the effects of magnetic treatment of irrigation water on surface tension and evaporation. As a result, four apparatuses with different characteristics were used. The application of a magnetic field influenced the water parameters, decreasing its surface tension by up to $24 \%$ and increasing its volume evaporated in relation to the raw water. Statistical analysis showed that our experimental results are significant.
\end{abstract}

Keywords: Magnetic device, Water Evaporation, Surface Tension, Statistical analysis.

\section{Introduction}

The degradation of water quality in Tunisia is mainly due to the overexploitation of groundwater, pollution and especially mismanagement in the different areas. Magnetic treatment methods can be used in the field of agriculture to alleviate salinity problems of irrigation. In recent years, the effects of magnetic fields on water have been of interest to physicists, chemists and biologists (Parsons et al., 1997). Smirnov (2003) stated that water, as a conductor of electromagnetic waves, can receive signals emitted by magnetic forces and thus becomes the mediator between the source of magnetic field and the plant. These results are endorsed by Pang and Deng (2008) who added that the application of a magnetic field creates changes in the physical and chemical properties of water at microscopic and macroscopic scales. In addition, Cai et al. (2009) explained these changes by the formation of a large number of hydrogen bonds. Today, magnetic processing is of interest to several sectors of activity such as health, environment, industry, etc. In particular, we are targeting its applications in agriculture.

Some authors claim favorable effects of magnetism technology on the effects of water such as the removal

*Corresponding author: Anis Elaoud

DOI: http://Dx.Doi.Org/10.14741/Ijae/5.3.4 of limestone deposits (Chibowski et al., 2003 and Alimi et al., 2006) in water pipes, improved germination rate and the stimulation of growth (Shabrangi et al., 2009). It should be noted, however, that the application in agriculture of this magnetism technology can take place either by directly exposing organs of the plant (such as seeds) to the magnetic field (Florez et al., 2007). Which is justified by the presence of Paramagnetic properties in the chloroplast, or via exposure of irrigation water to this magnetic field (Hozayn and Qados, 2010a)? This improvement can be attributed to the formation of new protein bands (Hozayn and Qados, 2010b). On the other hand, Celik et al. (2008) and Shabrangi et al. (2009) reported that this physical treatment affects gene expression by increasing biological reactions such as protein synthesis.

Magnetic water treatment devices are environmentally friendly, competitively priced and no energy requirements (Hozyan and Qados, 2010a) However, little research is directed at improving the characteristics of the magnetic machine and optimizing the parameters for treatment against the salinity of irrigation water. Thus, magnetized water used for irrigation can improve water productivity (Maheshwari et al., 2009), thus conserving water supply for the future in light of the expected global water shortage. Alkhazan and Saddik (2010), have 
shown that a magnetic field can physically and chemically affect water. The physical and chemical properties for samples were measured in addition to their bacterial content. In both cases of static and shaking, the magnitude of the magnetic flux is increased and the electrical conductivity (EC) is increased. Researchers observed that magnetized water helps in dissolving minerals and acids by a higher rate than unmagnetized water. This is in addition to dissolving oxygen and increasing the speed of chemical reactions (Moon and Chung, 2000).

Smirnov (2003) noticed that water can receive signals produced from magnetic forces that have a direct effect on living cells and their vital action. Clear inverse correlations between metallic pollutants concentrations and concentration-dependant magnetic characteristics are observed by Georgeaud et al. (1998) and Matasova et al. (2005). Krzemieniewski et al. (2004) revealed that the magnetization of tap water allows achieving its full oxygenation capacity.

The magnetized water used for irrigation can promote the development of the plant and increase its production (Dattatry and Vijaysinh, 2015). Taimourya et al. (2015) showed that the static magnetic field has positive effects such as stimulating growth and improving the production of cabbage (Brassica oleracea) of about $30 \%$. Elaoud A. et al. (2016) showed the effect of magnetic treatment on water quality and on the yield of the melon culture which increased by 39 $\%$ compared to the control (raw water).

Surface tension is one of properties of magnetic treatment water. Huo et al. (2011), found a decreasing tension coefficient on the surface of normal and deionized water, reaching a minimum value around 0.4 T - 0.7 T of magnetic treatment. Pang \& Deng (2008) showed differences in surface tension of magnetic treatment water, based on the contact angle of a droplet on a smooth surface of copper and graphite. Finding that this angle is slightly lower than in the untreated water, which indicates a decrease in hydrophobicity. The above is in accordance with Otsuka and Ozeki (2006), results who observed that the contact angle of droplets of magnetized water was lower than that of untreated water, measured on a copper surface. Other authors (Amiri and Dadkhah, 2006 ; Cai et al., 2009 ; Toledo et al., 2013 and Hasaani et al., 2015) have verified a reduction in surface tension under different experimental conditions. Also, Cai et al. (2009) pointed out that a magnetic field can decrease the surface tension while increasing the viscosity of water.

Evaporation is one of the physical parameters water influenced with magnetic device. Yun-Zhu et al. (2012), reported that under a strong magnetic field (more than $8 \mathrm{~T}$ ), the evaporation rate increases significantly. This parameter depends on the surface of the liquid/gas interface, the change in the intensity of the hydrogen bonds and Van der Waals forces. Szcześ et al. (2011) point out an increase in the rate of evaporation of water after magnetization. Holysz et al.
(2007) also observed this trend, but they make clear that the rate of evaporation of magnetic treatment is altered if it contains electrolytes in solution, in which case a high concentration may cause the opposite effect. This is because the thickness of the hydration layer around the ions affects this property. Wu et al. (2006) showed that the evaporation of pure water has increased in a static magnetic field $(0.25,0.36$ and 0.55 $\mathrm{T})$ compared to evaporation outside the magnetic field.

Nakagawa et al. (1999) examined the effect of magnetic field on water vaporization. The magnetic field enhances the water vaporization in air, but not in nitrogen. Furthe more, the magnitude of these effects depends on the field gradient product $\mathrm{B} d \mathrm{~dB} / \mathrm{dx}$ field and the maximum of the vaporization rate increment is asymmetric to the field axis.

Farhan L.R. et al. (2013) small increase in evaporation rates took place after using magnetic field So, the magnetic field will increase the surface tension and lead to maximize the evaporation rate.

In this context, our subject arises in order to study the effect of magnetic fields on the physical and chemical parameters of water in order to bring about the improvement of the evaporation and tension surface.

\section{Materials and methods}

\subsection{Generality}

The study and analysis of the water was conducted at Laboratory of Natural Treatment Water - Water Research and Technologies Center - Borj Cedria, Tunisia.

The difference between the evaporated volume of the magnetized water and the evaporated volume of the not-magnetized water at a fixed temperature is $\Delta \mathrm{V}$ (Eq.1).

$\Delta \mathrm{V}=\mathrm{Ve}(\mathrm{M})-\mathrm{Ve}(\mathrm{NM})$

The experimental device is in complete random block to three repetitions. In each block contains 3 tests.

In this work, the magnetic devices (M1 = 3300 Gauss, M2 = 2900 Gauss, M3 = 5000 Gauss and Electromagnetic $\mathrm{m}=900$ Gauss) are mounted on experimental system in order to obtain magnetized water (Figure1).

We note Magnetized water (M) and Not-Magnetized water (NM).

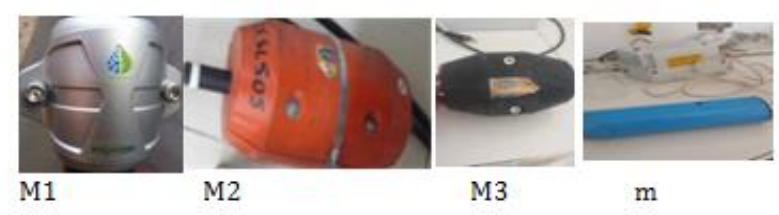

Fig.1 Magnetic devices mounted on the experimental system 


\subsection{Measurement of surface tension}

The experimenter carried out a large number of tests on surface tension of magnetized water. Magnetization condition mainly refers to intensity of magnetic field, magnetic course, temperature and water quality.

The method used to determine surface tension is the falling drop method. The drop which forms at the extremity of the burette (with $10 \mathrm{ml}$ volume) is subjected to two opposing forces:

- Its weight increases during the development of the drop.

- The force of the surface tension which retains it in contact with the glass.
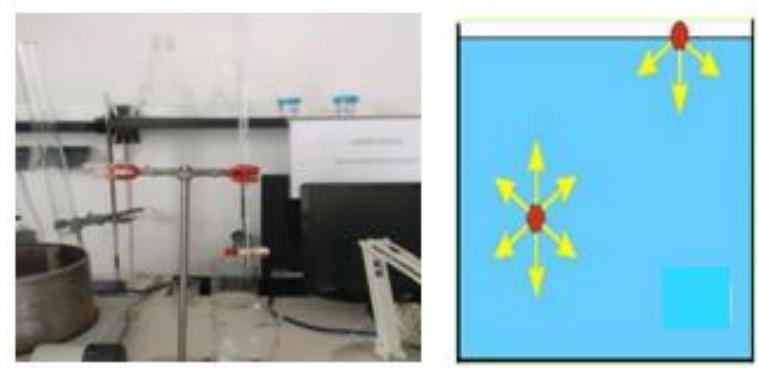

Fig. 2 Measurement of Surface Tension (ST)

\subsection{Measurement of evaporation}

Since the last century, many studies have focused on the effect of magnetic field on water, but the results of these studies were often contradictory. A large number of documents on the effect of the magnetic field on the physical and chemical properties of water were proposed. Most of the arguments are actually related to chemicals in water and not related to the properties of the water itself. Other studies investigated the effect of a magnetic field on the physical and chemical properties of pure water yielded inconsistent results (Cai et al.). In this Framework, we studied the influence of the magnetic field on the evaporation of water.

In order to better understand the physico-chemical modifications of the water following a magnetic treatment, an evaporation test was carried out. To do this, we need:

- Two graduated beaker of $80 \mathrm{ml}$

- An evaporation bath

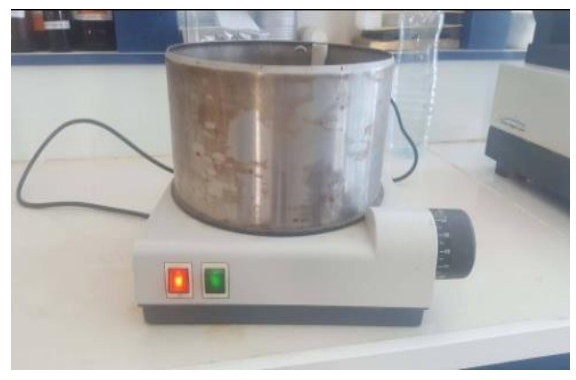

Fig.3 Evaporation system
Evaporation of the samples, with temperatures between $50{ }^{\circ} \mathrm{C}$ and $100{ }^{\circ} \mathrm{C}$ for one hour were carried out on magnetized water and raw water to a volume of $80 \mathrm{ml}$. The difference of the evaporated volume [Magnetized (M) and Not-Magnetized water (NM) in $\mathrm{ml}]$

\subsection{Statistical Analysis}

The results data were submitted to an analysis of variance at a $5 \%$ significance level. The effects of the variables were studied by regression analysis. All statistical analyses were performed using the Excel specific program (Statistical). The analysis based on the coefficient of determination and the significance of regression coefficients. The significance of coefficients was estimated by t-test and p-values. The higher the level of the $t$-value and the lower the $p$-value, the more significant is the coefficient (Khuri et al., 1987).

The sign of each coefficient suggests the direction of the relationship. The elimination of insignificant variables gives more accurate forecasts according to Sonmez and Rowings (Sonmez et al., 1998). The $\mathrm{R}^{2}$ have been widely used for model evaluation, these statistics are oversensitive to high extreme values and insensitive to additive and proportional differences between model predictions and measured data (Legates et al., 1999).

\section{Results and discussion}

The objective of this study is to value the influence of the magnetic device on water (surface tension and evaporation).

The monitoring of the variation of the surface tension and evaporation of the water samples of the well, after magnetic treatment.

\section{* Study of Tension surface}

This work shows the surface tension decrease in magnetized water and the evaporation increase during magnetic tracing. This variation depends on the temperature of water and intensity of magnetic device.

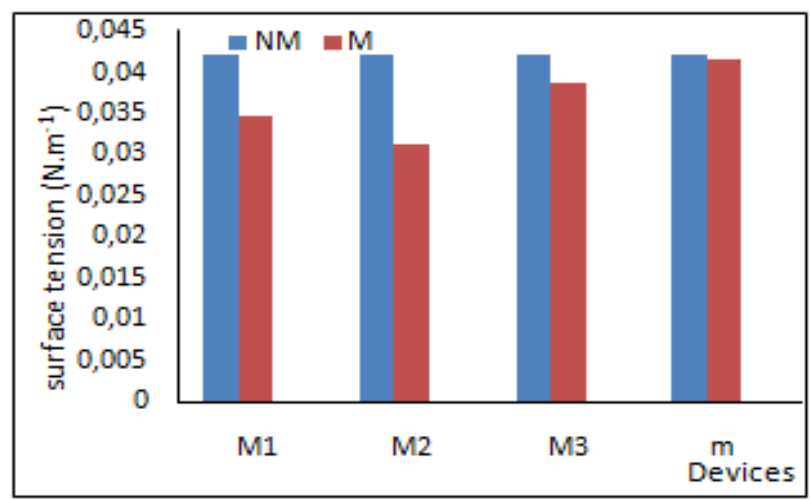

Fig.4 Effect of magnetic treatment of water on Surface Tension (ST) 
The magnetic treatment of the water leads to a significant reduction in the surface tension.

In this context, it is noted that M2 shows a greater effect than other magnetic devices. The water treated with M2 illustrates a reduction of $24 \%$ in the surface tension compared to the untreated water.

The electromagnetic $(\mathrm{m})$ verified a very small variation in the surface tension of the water.

This confirms that change a $68.9 \%$ (between M2 and $\mathrm{m}$ ) in magnetic field intensity results a variation of $23 \%$ in surface tension.

Toledo et al. (2013) have verified that a magnetic field increases the surface tension.

\section{* Study of Evaporation}

This section examines the effect of magnetic treatment on evaporation of water. The results of the tests in the figure below shows that for one hour:

- For $50^{\circ}, 80^{\circ}$ and $100^{\circ} \mathrm{C}$, all the devices favored evaporation of the water compared to the control.

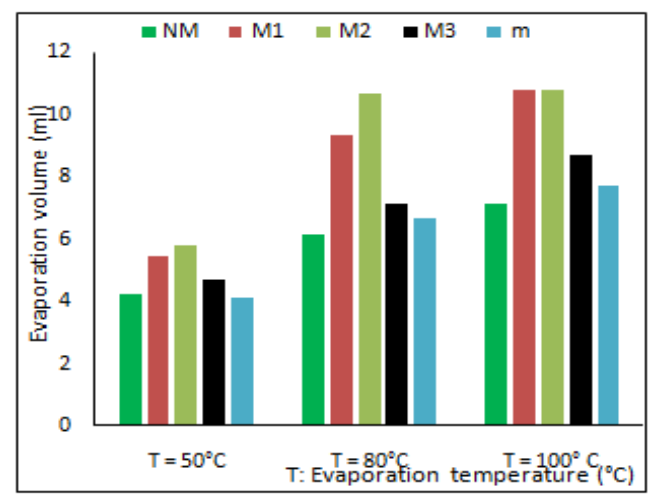

Fig.5 Effect of magnetic water treatment with different temperatures and devices

The magnetic device M2 records the highest evaporated volume. Figure 5 illustrate a difference of the evaporated volumes recorded between the quantity of water magnetized (M) with the apparatus $\mathrm{M} 2$ and the water not magnetized (NM) at $\mathrm{T}=50^{\circ} \mathrm{C}: \Delta \mathrm{V}$ $=6-4=2 \mathrm{ml}$. Respectively for a temperature $\mathrm{T}=80^{\circ} \mathrm{C}$ : $\Delta \mathrm{V}=4.5 \mathrm{ml}$.

This experiment shows the effect of temperature on the evaporation of magnetized water.

Table1 Effect of the magnetic treatment on evaporation volumes ( $\mathrm{ml}$ ) with two intensities and temperatures

\begin{tabular}{|c|c|c|c|c|c|c|}
\hline $\begin{array}{c}\text { Temperature/ } \\
\text { Devise }\end{array}$ & \multicolumn{3}{|c|}{$\begin{array}{c}\text { M1 } \\
(3300\end{array}$} & \multicolumn{3}{|c|}{$\begin{array}{c}\text { M2 } \\
\text { (2900G) }\end{array}$} \\
\hline $\mathbf{5 0}^{\circ} \mathbf{C}$ & 5.4 & 5.3 & 5.4 & 5.8 & 5.8 & 5.8 \\
\hline $\mathbf{8 0}^{\circ} \mathbf{C}$ & 9.4 & 9.4 & 9.3 & 10.7 & 10.6 & 10.7 \\
\hline
\end{tabular}

For $50^{\circ} \mathrm{C}$ : $\mathrm{M} 2$ records the highest evaporated volume of $6.9 \%$ with respect to $\mathrm{M} 1$ and $80^{\circ} \mathrm{C}$ with an evaporated volume difference of $12.1 \%$.
The evaporated volume is influenced by the intensity of the magnetic field and the temperature.

\section{* Relation between tension surface and evaporation}

The lowest value of the surface tension was recorded with the M2 apparatus by a $24 \%$ decrease compared to the control. For water evaporation, M2 showed a high evaporated volume at all temperatures

This gives us a relation between the surface tension and the evaporation. Indeed, when the surface tension decreases the evaporated volume increases

The results of this study of the effect of magnetic devices on water are consistent with Farhan L.R. et al. (2013) small increasing in evaporation rates were take place for using magnetic field if compared with the absence of magnetic field. Because? the magnetic devise will increase the surface tension and lead to maximize the evaporation rate.

Our results are in line with Yun-Zhu et al. (2012), when he showed that under a strong magnetic field, the evaporation rate increases significantly. This parameter depends on the change in the intensity of the hydrogen bonds and on the surface of the liquid/gas interface.

\section{* Statistical analysis}

We observe the high significance of results of Evaporation with a regression R (0.83) (Table 2).

To test the significance of the regression analysis of variance (F-test) is performed according to the standard procedure.

If the calculated $F$ value is greater than the $F$ critical value, there is a real relation between dependent and independent variables. This test follows an Fdistribution with degree of freedom (d.o.f) $v=2$, so that the critical region will consist of a value exceeding 0.00079148 . The calculated $F$-value $(F=13.7277562)$ is greater than the critical F-value $(0.00079148)$. As the Fisher F-value observed is much greater than the critical value $\mathrm{F}$, which confirms the high significance of the testing of evaporation of magnetized or notmagnetized water (Table 3).

Using table 4, the model of Evaporation (Ev) is written (Eq.2):

$\mathrm{Ev}=-0,173+0,085 \mathrm{~T}+3.74810^{-4} \mathrm{I}$

( $\mathrm{T}$ : Temperature and I : Intensity of magnetic)

The probability (Tab 4) can help us to state that temperature is the most influential parameter in the process $(\mathrm{P}=0.00036<<0.05)$.

The calculated F-value for Surface Tension $(F=1.2)$ is greater than the critical F-value $(0.3)$ which confirms the significance of the testing of Surface Tension of water with regression $\mathrm{R}(0.54)$, (Table 5 and 6). The model of the surface tension (ST) extracted of the table 7 is written (Eq.3):

$\mathrm{ST}=0.04-1.2410^{-6} \mathrm{I}$

(ST : Surface Tension and I : Intensity of magnetic) 
Table 2 Statistical regression of Evaporation (Ev)

\begin{tabular}{cc}
\hline \multicolumn{2}{c}{ Statistical regression } \\
\hline Multiple determination coefficient & 0.83 \\
Coefficient of determination $\mathbf{R}^{2}$ & 0.69 \\
Standard Error & 1.39 \\
Observations & 15 \\
\hline
\end{tabular}

Table 3 Analysis of variance of Evaporation (Ev)

\begin{tabular}{cccccc}
\hline & $\begin{array}{c}\text { Degree of } \\
\text { freedom }\end{array}$ & $\begin{array}{c}\text { Sum of } \\
\text { squares }\end{array}$ & $\begin{array}{c}\text { Average of } \\
\text { squares }\end{array}$ & F & $\begin{array}{c}\text { Critical } \\
\text { value of F }\end{array}$ \\
\hline Regression & 2 & 53.3585439 & 26.679272 & 13.7277562 & 0.00079148 \\
Residues & 12 & 23.3214561 & 1.94345467 & & \\
Total & 14 & 76.68 & & & \\
\hline
\end{tabular}

Table 4 Analysis of coefficients and probabilities of Evaporation (Ev)

\begin{tabular}{crcrc}
\hline & Coefficients & Standard Error & Statistical t & Probability \\
\hline Constant & -0.17278615 & 1.47119598 & -0.11744604 & 0.90844947 \\
Variable T & 0.08573684 & 0.01751746 & 4.89436606 & 0.00036944 \\
Variable I & 0.00037485 & 0.00020034 & 1.87101396 & 0.08591821 \\
\hline
\end{tabular}

Table 5 Statistical regression of Surface Tension (ST)

\begin{tabular}{cc}
\hline \multicolumn{2}{c}{ Statistical regression } \\
\hline Multiple determination coefficient & 0.54 \\
Coefficient of determination $\mathbf{R}^{2}$ & 0.29 \\
Standard Error & 0.0044 \\
Observations & 5 \\
\hline
\end{tabular}

Table 6 Analysis of variance of Surface Tension (ST)

\begin{tabular}{cllccc}
\hline & $\begin{array}{c}\text { Degree of } \\
\text { freedom }\end{array}$ & $\begin{array}{c}\text { Sum of } \\
\text { squares }\end{array}$ & $\begin{array}{c}\text { Average of } \\
\text { squares }\end{array}$ & F & $\begin{array}{c}\text { Critical } \\
\text { value of F }\end{array}$ \\
\hline Regression & 1 & $2.4833 \mathrm{E}-05$ & $2.4833 \mathrm{E}-05$ & 1.22903397 & 0.34848076 \\
Residues & 3 & $6.0615 \mathrm{E}-05$ & $2.0205 \mathrm{E}-05$ & & \\
Total & 4 & $8.5448 \mathrm{E}-05$ & & & \\
\hline
\end{tabular}

Table 7 Analysis of coefficients and probabilities of Surface Tension (ST)

\begin{tabular}{ccccc}
\hline & Coefficients & Standard Error & Statistical t & Probability \\
Constant & 0.04065695 & 0.00335436 & 12.1206157 & 0.0012088 \\
Variable I & $-1.2404 \mathrm{E}-06$ & $1.1189 \mathrm{E}-06$ & -1.10861805 & 0.34848076 \\
\hline
\end{tabular}

\section{Conclusion}

The application of a magnetic field has influenced the physical parameters of the raw water by decreasing the surface tension and promoting evaporation. A $24 \%$ decrease in surface tension causes an increase in the evaporated volume of $42 \%$ at a temperature of $80^{\circ} \mathrm{C}$. According to the statistical analysis, the effect of magnetic treatment on surface tension and evaporation depends mainly on the magnetic field intensity, temperature and physicochemical parameters of the raw water.

Statistical analysis showed a high significance and the results gave a regression $\mathrm{R}(0.83)$.

Some mechanisms of the effect of magnetization on the structure of water, soil and assimilation of the plant are still not well known.

Further analyzes could provide answers to the questions concerning the phenomena which favor the efficiency of magnetic treatment and the improvement of the yield of the plant.

\section{References}

F. Alimi, M. Tlili, M. Amor, C. Gabrielli and G. Maurin (2006). Influence of Magnetic Field on Calcium Carbonate Precipitation. Desalination, 206: 163- 168.

M. Alkhazan and A. Saddiq (2010). The effect of magnetic field on the physical, chemical and microbiological properties of the lake water in Saudi Arabia. Journal of Evolutionary Biology Research, Vol. 2 (1), pp. 7-14.

M.C. Amiri, A.A. Dadkhah (2006). On reduction in the surface tension of water due to magnetic treatment. Colloids and Surfaces A: Physicochemical and Engineering Aspects, 278 (1-3), 252-255.

R. Cai, H. Yang, J. He et W. Zhu (2009). The Effects of Magnetic Fields on Water Molecular Hydrogen Bonds. Journal of Molecular Structure, 938:15-19. 
Ö. Çelik, Ç. Atak, A. Rzakulieva (2008). Stimulation of Rapid Regeneration by a Magnetic Field in Paulownia Node Cultures. Journal of Central Europ. Agric., 9 (2): 297 - 303.

E. Chibowski, L. Holysz, A. Szczes, M. Chibowski (2003) Precipitation of calcium carbonate from magnetically treated sodium carbonate solution. Colloids Surf. A, 225: 6373.

A. Elaoud, N. Turki, H. Ben Amor, R. Jalel and N. Ben Salah (2016). Influence of the Magnetic Device on Water Quality and Production of Melon. International Journal of Current Engineering and Technology, Vol.6, No.6 : 2256-2260.

L.R. Farhan (2013). The effect of Beta-radiation and magnetic field intensity on Ni-Cr alloy properties. Applied Chemistry, 54A (2013) 12686-12688.

M. Florez, M.V. Carbonell and E. Martinez (2007). Exposure of Maize Seeds to Stationary Magnetic Fields: Effects on Germination and Early Growth. Environ. Exp. Bot. 59:68-75.

V.M. Georgeaud, P. Rochette, J.P. Ambrosi, D. Vandamme and D. Williamson (1998). Relationship between heavy metals and magnetic properties in a large polluted catchment: The Etang de Berre (south of France). Phys. Chem. Earth, 22: 211-214.

A.S. Hasaani, Z.L. Hadi, K.A. Rasheed (2015). Experimental study of the interaction of magnetic fields with flowing water. International Journal of Basics and Applied Science 3 (3), 1-8.

L. Holysz, A. Szczes, E. Chibowski (2007). Effects of a static magnetic field on water and electrolyte solutions. J. Colloid Interface Sci. 316, 996-1002.

M. Hozayn and A. Qados (2010a). Irrigation With Magnetized Water Enhances Growth, Chemical Constituent and Yield of Chickpea (Cicerarietinum L.). Agriculture and Biology Journal of North America, 1(4): 671-676.

M. Hozayn and A. Qados (2010b). Magnetic Water Technology, a Novel Tool to Increase Growth, Yield and Chemical Constituents of Lentil (Lens esculenta) Under Greenhouse Condition. American-Eurasian J. Agric and Environ. Sci., 7(4): 457-462.

Z.F. Huo, Q. Zhao, Y.H. Zhang (2011). Experimental study on effects of magnetization on surface tension of water. Procedia Engineering, 26, 501-505.

J. Nakagawa, N. Hirota, K. Kitazawa, M. Shoda (1999). Magnetic field enhancement of water vaporization, J. Appl. Phys. 86, 2923-2925.

M. Krzemieniewski, M. Dbowski, W. Janczukowicz and J. Pesta (2004). Effect of the Constant Magnetic Field on the Composition of Dairy Wastewater and Domestic Sewage. Polish J. Environ. Stud., 13: 45-53.

A.I. Khuri, J.A. Cornell (1987). Response Surfaces, Marcel Dekker, New York.

D.R. Legates, G.J. McCabe (1999). Evaluating the use of 'goodness-of-fit' measures in hydrologic and hydroclimatic model validation. Water Resour. Res. 35: 233-241.

L. Maheshwari and H.S. Grewal (2009). Magnetic treatment of irrigation water: Its effects on vegetable crop yield and water productivity. Agricultural Water Management 96 : 1229-1236.
G.G. Matasova, A.Y. Kazansky, S.B. Bortnikova, and A.A. Airijants (2005). The use of magnetic methods in an environmental study of areas polluted with non-magnetic wastes of the mining industry (Sal air region, Western Siberia, Russia). Geochemistry: Explor. Environ. Analy., 10: 75-89.

J.D. Moon, H.S. Chung (2000). Acceleration of germination of tomato seed by applying an electric and magnetic field. $J$. Electro-Statistics, 48:103-114.

I. Otsuka, S. Ozeki (2006). Does magnetic treatment of water change its properties. Journal of Physical Chemistry B 110 (4), 1509-1512.

X.F. Pang and B. Deng (2008). The Change of Macroscopic Features and Microscopic Structures of Water Under Influence of Magnetic Field. Physica B 403: 3571- 3577.

S.A. Parsons, S.J. Judd, T. Stephenson, S. Udol and B.L. Wang (1997). Magnetically augmented water treatment Institution of Chemical Engineers, Trans IChemE, Vol 75, Part B.

J.V. Smirnov (2003). The Effect of a Specially Modified Electromagnetic Field on the Molecular Structure of Liquid Water. BioMagnetic hydrology. Global Quantec. Inc., U.S.A, pp. $122-125$

R. Sonmez and J. Rowings (1998). Construction labor productivity modeling with neuronal networks, Journal of construction engineering and management, Vol.124, N6. P. 498-504

A. Shabrangi and A. Majd (2009). Effect of Magnetic Fields on Growth and Antioxidant Systems in Agricultural Plants. PIERS Proceedings, Beijing, (China), 23-27.

A. Szczes, E. Chibowski, L. Holysz, P. Rafalski (2011). Effects of static magnetic field on water at kinetic condition. Chem Eng. Process. 50, 124-127.

H. Taimourya, E.H. Bourarach, A. ElHarif, N. Hassanain, L. Masmoudi, L. Baamal, M. Oussible (2015). Évaluation de la productivité du chou pommé (Brassica oleracea), sous l'effet de l'irrigation avec une eau traitée magnétiquement, dans la région de Casablanca (Maroc). Rev. Mar. Sci. Agron Vét. 3 (2):27-36.

E.J.L. Toledo, T.C. Ramalho, Z.M. Magriotis (2008). Influence of magnetic field on physical-chemical properties of the liquid water: Insights from experimental and theoretical models. J. Mol. Struct. 888, 409-415.

S.H. Wu, F.B. Zhang (2006). Effects of magnetic field on evaporation of distilled water. J. Petrochem. Univ. (China), 232, 954-954.

G. Yun-Zhu , Y. Da-Chuan , C. Hui-Ling , S. Jian-Yu , Z. Chen-Yan , L. Yong-Ming , H. Huan-Huan , L. Yue , W. Yan , G. Wei-Hong , Q. Ai-Rong, S. Peng (2012), Evaporation Rate of Water as a Function of a Magnetic Field and Field Gradient, Int. J. Mol Sci. 2012, 13, 16916-16928; doi:10.3390/ijms 131216916. 